\title{
Counselors in Rural Schools: A Position of Leadership
}

\author{
Cynthia L. Wimberly \\ University of Texas-Pan American \\ Stephanie Brickman \\ University of Texas-Pan American
}

\begin{abstract}
Approximately one-third of the K-12 student population attends school in areas identified as rural/small town. Rural schools offer counselors unique opportunities to lead by guiding students' education in directions that best fit their career aspirations, thus impacting the region educationally, economically and socially. The purpose of this paper is to identify the leadership role of school counselors in rural communities as identified by the American School Counselors Association (ASCA). Numerous challenges and opportunities inherent rural settings have been identified and suggestions offered as to ways in which counselors can effectively undertake leadership roles.
\end{abstract}

Keywords: school counselors; leadership

In relation to other professionals in the school system, for example, principal, teacher, nurse, the role of the school counselor is relatively new and constantly evolving in response to social, political, and economic demands. Due to these constant changes school counselors often have difficulty establishing a professional identity. This can be even more challenging in a small community where all counselor duties and responsibilities are visible. The purpose of this paper is to highlight the unique leadership role of a school counselor in a rural setting. Urban areas have access to numerous resources and support staff to provide the necessary services to students. In contrast, in rural settings the school counselor often is expected to take a leadership role in providing multiple services.

\section{Defining Rural Communities and School Districts}

Rural areas are defined as any area located outside an urban cluster or urbanized area. Urbanized clusters and urbanized areas are defined as consisting of "core census block groups or blocks that have a population density of at least 1,000 people per square mile and surrounding census blocks that have an overall density of at least 500 people per square mile" (U.S. Census Bureau, 2010, p.1). According to this definition, approximately a fifth of the public school population (19.3\% of students) is enrolled in a rural school district. If students enrolled in a locale defined as a town were added to this number, a third (34.2\%) of the nation's school age population attend classes outside a designated city or suburban area (National Center for Education Statistics, 2011;U.S. Census Bureau, 2010). This suggests that the rural school counselor, taking a leadership role, can have a significant impact on education in the United States.

According to the National Center for Education Statistics (U. S. Department of Education, 2007), rural schools can be broken down into several categories (Table 1).

Table 1

Students Attending Rural Schools in the United States

\begin{tabular}{ccccc}
\hline School district size & Town-schools & Town-Students & Rural-Schools & Rural--Students \\
\hline & & & & \\
Less than 200 & 2,537 & 215,016 & 10,741 & $1,054,676$ \\
$200-399$ & 4,311 & $1,320,478$ & 8,509 & $2,507,251$ \\
$400-799$ & 5,595 & $3,089,494$ & 7,621 & $4,206,179$ \\
$800-1,199$ & 1,050 & 994,048 & 1,502 & $1,427,856$ \\
$1,200-1,999$ & 368 & 539,794 & 576 & 850,139 \\
2,000 or more & 28 & 63,958 & 106 & 261,914 \\
\hline
\end{tabular}

These rural school districts are located predominantly in the South and Midwest and have a greater proportion of students identified as white. Overall, in these districts fewer high school graduates continue on to college and a smaller percentage of adults have a bachelor's degree. Finally, median earnings, when adjusted for geographic cost differences regardless of educational attainment, are usually higher for adults working full-time in a rural area as compared to those in cities or towns. However, these salaries are lower than for adults working full time in suburban areas (U.S. Department of Education, 2007). 
Rural students are not limited to a formal postsecondary education to develop the knowledge and skills to be successful in their chosen careers. Many rural areas are economically sustained through farming and/or ranching operations, and are viewed by rural land owners as being vital to meeting the nation's food demand and economic growth. Students in a rural area, through a lifetime of mentoring and practice, are prepared by elders to continue the farming and ranching operations. Therefore, a school counselor must realize that post-secondary education is valued differently in rural areas than in urban areas (Brickman $\&$ Wimberly, 2014). School counselors who are unfamiliar with rural settings must realize that financial stability and social status are gained from maintaining the farming and ranching industry.

Another characteristic of rural settings is many individuals live in relative isolation. The number of students continues to decline in rural areas due to the mobility of families (Cadwallader, 1992). Moreover, Schafft (2006) reports that any increase in student population is likely to be arise from transient, impoverished families who may move in and out of small neighboring communities to meet their basic needs, such as affordable housing and available jobs (Colton, 2004). Because of poverty and movement between schools, such students are inclined to have a higher frequency of academic and social needs (Wood, 1993). These factors contribute to an increased dependency on the stable core community to satisfy personal, social and academic needs (Schafft, 2006). In comparison, in urban areas individuals can more easily move in and out of various groups, neighbors and schools to satisfy specific individual, academic and social needs (Hines, 2002; Saba, 1991; Sutton \& Pearson, 2002).

The reverse of this situation is that students who do not "fit in" in small towns/rural communities do not have an alternative group with which to interact. In addition, for all students, unless the family makes an effort to expose them to outside areas, the way it is at home, is the only way for life to be. There is little exposure to different ways of living or thinking for students who have a strong identity with community and those who do not. Frequently, both groups are satisfied with the status quo with little impetus to expand their experiences (Sutton \& Pearson, 2002).

Not only are the rural conditions unique, but school counselors in small towns/rural areas also encounter a unique group of students. The young people who are reared in these areas have a strong sense of belonging; this is home. They know the area geographically and historically and develop a strong sense of self in being in the community. Many have attended the same school, with the same classmates, teachers, and routines since enrolling in prekindergarten classes.
They walk the same halls, have classes in the same rooms, and participate in many of the same activities as their parents and grandparents (Saba, 1991; Sutton $\&$ Pearson, 2002). Clearly rural regions have unique characteristics with which the school counselor must contend; however, to understand the impact of the school counselor in rural areas requires understanding the history of guidance and counseling in school systems.

\section{History of the School Counselor}

At the start of the last century, the school counselor was frequently considered a vocational guidance counselor, responsible for assisting students in the transition from school to a career. With the ending of World War II and the spotlight on psychology and mental health, a school counselor's role changed to targeting students with learning, social, or psychological problems. By the 1980s, school counseling expanded from a remedial focus to providing services to all students by integrating the program into the total school focus (Dahir \& Stone, 2012).

Recently, the educational profession has implemented a comprehensive school counseling program, which is considered an integral part of the school environment, to assist all students to achieve academic success (American School Counselor Association [ASCA], 2005; Bardhoshi \& Duncan, 2009). In continuation of this movement toward impacting the school system for the betterment of all students, school counselors have been given the opportunity to take a leadership role and move toward a more defined professional identity (American School Counseling Association, 2012). The path to a more defined identity for the rural counselor begins with the many roles he/she has in the school and community.

\section{Unique Roles of a Rural School Counselor}

In rural settings counselors are often required to serve many roles, a challenge that can be difficult for a new counselor (Sutton \& Pearson, 2002). Owing to lack of resources, school counselors in rural/small town areas often fulfill more professional duties than their counterparts in urban schools. By necessity, rural counselors wear many hats. As the sole school counselor in the campus or district, all services mandated by the position must be provided (for example, guidance lessons, career and postgraduate information, individual/group counseling, crisis counseling, responsive services, and consultation with faculty and parents) (ASCA, 2012). In addition, many counselors often are: (a) assigned the role of testing coordinator, (b) involved in assisting in the execution 
of disciplinary actions, (c) identified as an administrative assistant unofficially, and (d) charged with identifying and tracking special populations (i.e. gifted/talented programs, at-risk programs, special education programs, 504 programs) (MonteiroLeitner, Asner-Self, Milde, Leitner, \& Skelton, 2006). The rural school counselor is a generalist, not a specialist, with no opportunity to concentrate in one specific area as sometimes possible in an urban area, (i.e. coordinate college applications or counsel those with substance abuse issues) (Saba, 1991).

The issue of understaffing has implications beyond the school doors. The school counselor is often the only mental health provider in the area. Since there is no one to whom the counselor may refer a student or family, he/she may be called upon to assist in providing community mental health resources for the community (Bardhoshi \&Duncan, 2009; Saba 1991; Sutton, 1988).

In summary, in rural areas, there is typically one school counselor in the district (Bardhoshi \& Duncan, 2009; US Department of Education, 2007).

Community members may call the school counselor by name and will most likely be aware of the counselor's personal life, as well as his/her professional roles at school (Saba, 1991; Sutton \& Pearson, 2002). The school counselor must understand the unique culture of the community and accept a high-level of visibility in working with a unique student population whose parents and relatives may be school board members, fellow teaching colleagues, or pillars in the community. These same pillars of the community will expect the rural school counselor to participate in significant community activities such as the local stock show. A school counselor from an urban area may initially experience cultural shock on entering a diverse school environment (Rollins, 2010). In a rural setting, understanding diversity includes appreciating what supports rural education, the social environment, and a rural economy.

However, school counselors who choose to stay in a rural area eventually are seen as "one of us" and because of the small population gain knowledge of families, the connections, and the issues of the community quickly (Sutton \& Pearson, 2002). In conclusion, the working environment for the school counselor in a small/rural area creates many unique challenges that lead to many distinctive opportunities to impact students and the community. A school counselor, who is mindful of the rural environment, may then be ready to take on a leadership role. This position is more than a job; rather, it is a lifestyle that influences many students and their families in rural areas.

\section{Leadership for School Counselors}

The American School Counselor Association (ASCA) model emphasizes leadership. Although the principal is identified as occupying the main position of leadership, the school counselor must assume leadership roles in the school system to promote student success in order to impact the greatest number of students. School counselors bring a unique set of skills to a leadership role, including knowledge of cultural diversity, the impact of poverty on learning, the ability to build consensus, and the influence of family dynamics on the learning environment (ASCA, 2012; Stone \& Clark, 2001).

School counselors are in a distinctive position to play a leadership role (Bardhoshi \& Duncan, 2009; Worzbyt \& Zook, 1992). According to the ASCA National Model (2012), all school counselors should practice leadership to ensure the academic success of each student. The school counselor in small town/rural school systems is uniquely situated to provide this leadership role through advocating, collaborating and coordinating services, consulting, and promoting systematic change (Hines, 2002; Worzbyt \& Zook, 1992).

Leadership Roles: Working with the Principal,
Advocacy, Collaboration, and Systems Thinking

Key to the counselor's leadership role is partnering with the identified school leader, the principal. Traditionally, principals have refused to view school counselors as leaders (Dahir \& Stone, 2012). This viewpoint is especially detrimental to the counseling program because of the amount of control the principal exercises in defining the implementation and maintenance of a school counseling program (Dahir \& Stone). Rural school districts are more likely to hire young, inexperienced counselors because retention of school counselors in a rural community is difficult due to the lack of available amenities and social life. The lack of professional experience can diminish school personnel's perception of the counselor as a leader even more (Whiston, 2002).

However, in a small school district, the lines are not so clearly drawn between administration and staff. Pearson and Sutton (1999) quoted a counselor in a small district who observed:

Clearly, my principal is my boss, but this is a small school, so she's also my colleague. Officially we meet once a week; informally, we see each other all the time. Our relationship is collegial rather than hierarchical. We can bounce ideas off each other, and even if we disagree about something, we can usually find some common ground to operate on. (p. 93) 
This relationship can be both beneficial and harmful. Because principals see counselors as "partners in the teaching and learning process" (Dahir, 2000, p. 74), school counselors in these districts are expected to perform tasks identified as inappropriate by ASCA. The principal assumes, because the duties are important to the functioning of the school, school counselors will perform non-counseling assignments. In a spirit of fair-practices, counselors usually agree to accept the assignment of non-guidance activities (Bardhoshi \& Duncan, 2009).

By willingly agreeing to accept non-guidance activities, with time, the counselor can use these experiences to gain knowledge of the inner workings of the school. This knowledge strengthens the leadership role and allows him/her to acquire the data needed to justify reassigning many of these duties to others based on the positive impact the counseling duties are having on the school environment. This must be done slowly. As a counselor combines practical on-site information with information on current program procedures and up to date technology obtained during the acquisition of a counseling degree, a more efficient counseling program can be developed (Monteiro-Leitner, et al., 2006). A strong working relationship with the principal, along with documentation of progress, provides the foundation for the counselor to be seen as a leader by the principal and the community.

School counselors can play an important leadership in the area of advocacy. Advocacy is defined in counseling as "identifying groups of people who might benefit from increasing their own strength" (Dahir \& Stone, 2012, p.124 quoted from Lewis, Lewis, Daniels, \& D'Andrea, 1998, p. 25). In small town/rural districts, advocacy may include the school counselor taking a stand against certain accepted practices and traditions. For such advocacy to be successful, the school counselor must develop a supportive relationship with the important stakeholders in the district. In rank of importance, the students are the first priority. School counselors must know their students, including socioeconomic status, educational barriers, cultural morés, and handicapping conditions both within and out-side of the educational environment. Due to a lack of community and school resources, school counselors must be willing to confront issues of system inequality, racism, bullying, unequal patterns of enrollment in advanced coursework, and all areas of educational injustices that contribute to the academic failure of students (Hines, 2002). However, movement in this area must be made cautiously with some stakeholders, as not all will value empowering all students (Mitcham-Smith, 2007).
The second area of importance regarding leadership, collaboration and coordination of services, is defined as:

prioritizing, organizing, and delivering the components of the school counseling program, e.g. individual/group counseling, classroom guidance lesson, consultation services, career and academic advising, and systemic support, so that you can increase the likelihood that the program will successfully affect the personal/social, career, and academic outcomes of every student in the school. (Dahir \& Stone, 2012, p. 391)

In a small school district, this is a way of life. The school counselor may also be the testing coordinator, at-risk coordinator, parent coordinator, chairman of the senior class, and any number of additional titles. To be productive, the school counselor must coordinate the different obligations, resources, and personnel in the district to positively impact the students and the school environment (Worzbyt \& Zook, 1992).

The utilization of consultation skills is standard for counselors in these districts. Because the area is small, both the physical smallness of the facility and the organizational smallness of the employees, faculty and staff must work in harmony to complete the educational mandates. This facilitates interaction among faculty, staff, parents, community and students. Consultation, defined "as a problem-solving approach with the adults in a student's life that are in a position to affect positive changes" (Dahir \& Stone, 2012, p.355) allows the counselor with specific expertise to collaborate with others to find consensus. Because of the smallness, the school counselor in these districts can connect easily with others and create strong relationships that allow all students to benefit from the connections.

Finally, schools are a system. As a system, the occurrence of one event impacts all aspects of the environment. School counselors occupy a unique position to identify systemic barriers to student success due to their access to school wide data, personal and professional relationships, and insight into the school climate. School counselors utilize this information to support systemic change (ASCA, 2012). Below are examples of how these different roles blend to allow the school counselor to impact students in small town/rural areas.

\section{Practice}

Specific suggestions for ways to strengthen a rural counselor's leadership role are described below. First and foremost, the counselor must know the community and the students. Connections must be made and nurtured. Possible suggestions would be attending a local church, joining a service organization, attending 
community events, or perhaps most importantly, living within the community. Counselors should learn student names and information about families and relationships. It is important to remember that not only does everyone know everyone else in a small community, but also many are related. Personal relationships have long histories and the counselor is the new person. Person to person contact is vital in opening lines of communication and being accepted as a member of the community (Saba, 1991; Worzbyt \& Zook, 1992). Once relationships are established the counselor may find the following actions helpful:

1. Utilize the school improvement committee in an advisory position to the school counseling program to align program goals with school goals (Worzbyt \& Zook, 1992).

2. Create an appropriate "brand" for business cards and brochures describing the school counseling program by incorporating school colors and mascots but with an individual twist (Worzbyt \& Zook, 1992).

3. Publicize the school counseling program's desired goals and achieved successes through informational meetings, articles in the local newspapers, "signs" posted in local businesses or on town marquees, speaking at local service clubs, and the incorporation of counseling goals into school goals (Sutton \& Pearson, 2002; Worzbyt \& Zook, 1992).

4. Address the school board to publicize goals, accomplishments, and plans for the future at least once a year.

5. Accept a campus leadership role when the principal is off-campus. When this happens, the counselor is elevated to a position of leadership in the eyes of the school and community (Bardhoshi \& Sutton, 2009; Gysbers \& Henderson, 2000; Monteiro-Leitner, et.al, 2006; Pearson \& Sutton, 1999). However, this can be detrimental to the counselor if clear boundaries are not set. A counselor should not be responsible for discipline decisions; however, it may often be necessary to monitor the situation and follow the procedures described in the handbook to maintain student discipline and safety. Upon the return of the principal, an official discipline decision is then made.

6. Accept sponsorship of extracurricular activities or special events as "fair duties" assignments by searching for those that best fit the goals of the counseling department (Bardhoshi \& Duncan, 2009; Monteiro-Leitner, et al., 2006; Pearson \& Sutton, 1999; Worzbyt \& Zook, 1992). For example, as sponsor of the National Honor Society, NHS students can welcome new students into the school (Monteiro-Leitner et al., 2006).

In context of fair duties assignment, counselors in small rural areas must be perceived as team players. This can be done by volunteering in concession stands, attendance at sporting events, plays, and band concerts, assisting at all grade levels possible, and sponsoring appropriate events. At each of these, the school counselor becomes more visible and in-tune with the community through these interactions and has the opportunity to publicize the counseling program, goals, and activities (Bardhoshi \& Duncan, 2009; Monteiro-Leitner, et.al, 2006; Worzbyt \& Zook, 1992).

Many students in rural areas do not perceive enrollment at a major university as a possibility. By contacting alumni (often in the post office or grocery store), counselors can provide opportunities for them to connect directly with potential students for certain universities. This personal touch makes the idea of attending a major university more realistic. Through a leadership role, the counselor has advocated for students who would not consider a major university, coordinated services to ensure the student has met degree requirements and involvement in extracurricular activities, completed the application/financial aid process, and consulted with community leaders to provide students with an opportunity to attend a major university.

The school counselor is perfectly situated to promote systematic change in a small district because coordinating services, advocating for change, and consulting with stakeholders are consistent with the daily routine of the school counselor. In so doing, the counselor becomes a leader for the school.

\section{Conclusion}

Although attention has started to focus on the role of the typical school counselor, the school counselor in small/rural areas has been neglected. School counselors in these areas not only must address the same issues as their counterparts in large urban areas, but they must also deal with issues unique to this environment. But in so doing, they have the opportunity to impact students and their families in ways counselors in larger school districts do not.

The ASCA (2012) model calls upon school counselors to provide leadership. Because of the unique position in small/rural school districts, the school counselor may occupy a legitimate position of power fundamental in creating a caring, nurturing, and a demanding academic school environment. Once the 
counselor has established a professional identity, become familiar with the local environment, and identified the program's goals, he/she may impact change. If, as Cole (1988) describes, rural schools are the emotional center of the community, then the school counselor can be the heart of the school. By providing effective leadership in the environment of the school and the community, the school counselor can have a positive impact on the region educationally, economically and socially through the education of the students who attend the rural schools.

\section{References}

American School Counselor Association, (2005). The ASCA national model: A framework for school counseling programs. Alexandria, VA: Author.

American School Counselor Association, (2012). The ASCA national model: A framework for school counseling programs. Alexandria, VA: Author.

Bardhoshi, G., \& Duncan, K. (2009). Rural school principals' perceptions of the school counselor's role. The Rural Educator, 30(3), 16-24.

Brickman, S.J. \& Wimberly, C. L. (in-press). The role of future goals, instrumentality and self-regulation in life career development. Psychology and Education.

Cadwallader, M. 1992. Migration and residential mobility. Madison, WI: University of Wisconsin Press.

Cole, B. (1988). Teaching in a time machine: The "make-do" mentality in small-town schools. Phi Delta Kappan, 70(2), 139-172.

Colton, R.D. 2004. Paid but unaffordable: The consequences of energy poverty in Missouri. Washington, DC: National Low Energy Housing Consortium.

Dahir, C.A. (2000). The national standards for school counseling programs: A partnership in preparing students for the new millennium. NASSP Bulletin, 84(616), 68-77. doi: $10.1177 / 019263650008461611$

Dahir, C.A., \& Stone, C.B. (2012). The transformed school counselor. Belmont, CA:Brooks/Cole.

Gysbers, N. C., \& Henderson, P.G. (2000). Developing and managing your school guidance program $\left(3^{\text {rd }}\right.$ ed.). Alexandria, VA: American Counseling Association.

Hines, P. L. (2002). Transforming the rural school counselor. Theory into Practice, 41(3), 192-201.

Mitcham-Smith, M. (2007). Advocacy-professional school counselors closing the achievement gap through empowerment: A response to HipolitoDelgado and Lee. Professional School Counseling, 10(4), 341-343.

Monteiro-Leitner, J., Asner-Self, K.K., Milde, C., Leitner, D.W., \& Skelton, D. (2006).The role of the rural school counselor: Counselor, counselor-inlaw training and principal perceptions. Professional School Counseling, 9(3), 248-251.
National Center for Education Statistics. (2011). Percentage distribution of children under 18 living in families, by poverty level, age group, and locale. US Department of Education. Retrieved from http://nces.ed.gov/pubs2007/ruraled/tables/tablea1_ 7.asp

Pearson, R. E., \& Sutton, J.M. (1999). Rural and small town school counselors. Journal of Research in Rural Education, 15(2), 90-100.

Rollins, J. (2010). Learning the ropes of rural counseling. Counseling Today, 52(10), 36-40.

Saba, R.G. (1991). The rural school counselor: Relationship among rural sociology, counselor role, and counselor training. Counselor Education \& Supervision, 30(4), 322-330.

Schafft, K. A. (2006). Poverty, residential mobility, and student transiency within a rural New York school district. Rural Sociology, 71(2), 212-231.

Stone, C. S. \& Clark, M. A. (2001). School counselors and principals: Partners in support of academic achievement. NASSP Bulletin, 85(624), 46-53. doi: $10.1177 / 01926365010856240$

Sutton, Jr. J. M. (1988). Work environment perspectives of school guidance counselors in isolated settings. Research in Rural Education, $5(1)$.

Sutton, Jr. J. M., \& Pearson, R. (2002). The practice of school counseling in rural and small town schools. Professional School Counseling, 5(4) 266-277.

United States Census Bureau. (2010). 2010 census urban and rural classification and urban area criteria. Retrieved from F: $\mid a r t i c l e s \backslash L e a d e r s h i p$, rural, sc 2010 Urban and Rural Classification Geography - U. S. Census Bureau.mht

United States Department of Education. (2007). Status of education in rural America. Retrieved from http://nces.ed.gov/bpubs2007/ruraled/tables/table1 2.asp

Whiston, S. C. (2002). Response to the past, present, and future of school counseling: Raising some issues. Professional School Counseling, 5(3). 148155.

Wood, D., N. Halfon, D. Scarlata, P. Newacheck, \& Nessim, S. (1993). Impact of family relocation on children's growth, development, school function, 
and behavior. Journal of the American Medical

Association, 270(11), 1334-38.
Worzbty, J.C., \& Zook, T. (1992). Counselors who make a difference: Small schools and rural settings. School Counselor, 39(5) 344-351.

\begin{abstract}
About the Authors:
Cynthia Wimberly, PhD, LPC-S, an Assistant Professor in the Department of Educational Psychology, University of Texas Pan American, has 30 years of experience in public schools. Her research is in school counseling, rural schools, at-risk students, and Logotherapy/Existential Analysis. Email: wimberlyc@utpa.edu

Stephanie Brickman, PhD, Associate Professor in the Department of Educational Psychology, University of Texas Pan American, is a Licensed Professional Counselor. Her research is in achievement motivation and is focused on students at risk. Email: sjbrickman@utpa.edu
\end{abstract}

